\title{
La conquista religiosa del encierro. Pentecostalismo y estrategias de gobierno en el sistema carcelario argentino
}

\author{
Mauricio Manchado \\ Consejo Nacional de Investigaciones Científicas y Técnicas de la República Argentina (CONICET). \\ Universidad Nacional de Rosario (UNR). Rosario. Argentina. \\ Email: mauriom@steel.com.ar
}

\begin{abstract}
Resumen: El artículo se propone indagar sobre el papel que ocupa el dispositivo religioso-evangélico-pentecostal, en tanto táctica de gubernamentalidad, en la gestión del encierro a partir de la descripción de su origen, crecimiento y consolidación en las cárceles santafesinas (Argentina). Prácticas y discursos que fueron objeto, por parte del servicio penitenciario, de rechazo absoluto, luego aceptación moderada y finalmente acción coordinada. En ese sentido, buscaremos reflexionar también sobre el ordenamiento social, el conjunto de reciprocidades y las narrativas que lo caracterizan, ya que esto nos permitirá comprender los sentidos que habilitan y sustentan dicho posicionamiento en el entramado de una institución punitiva como la prisión en la provincia de Santa Fe.
\end{abstract}

Palabras claves: Evangelismo; gubernamentalidad; cárcel; reciprocidades; narrativas

\section{The religious conquest of the confinement. Pentecostalism and government strategies in the Argentine prison system}

\begin{abstract}
The article aims to investigate the role of the religious-evangelical-pentecostal device, as a tactic of governmentality, in the management of the confinement based on the description of its origin, growth and consolidation in the prisons of Santa Fe (Argentina). Practices and speeches that were object, on the part of the penitentiary service, of absolute rejection, then moderate acceptance and finally coordinated action. In this sense, we will also seek to reflect on the social order, the set of reciprocities and the narratives that characterize it, since this will allow us to understand the senses that enable and sustain this positioning in the framework of a punitive institution such as the prison in the province of Santa Fe.
\end{abstract}

Keywords: evangelism; governmentality; prison; reciprocities; narratives

\section{A conquista religiosa do confinamento. Pentecostalismo e estratégias governamentais no sistema prisional argentino}

Resumo: O artigo propõe-se indagar sobre o papel desempenhado pelo dispositivo religioso-evangélico-pentecostal, como tática de governamentalidade, na gestão do confinamento baseado na descrição de sua origem, crescimento e consolidação nas prisões de Santa Fé (Argentina). Práticas e discursos que foram objeto, por parte do serviço penitenciário, de rejeição absoluta, depois aceitação moderada e finalmente ação coordenada. Nesse sentido, buscaremos também refletir sobre a ordem social, o conjunto de reciprocidades e as narrativas que a caracterizam, pois isso nos permitirá compreender os sentidos que possibilitam e sustentam esse posicionamento no marco de uma instituição punitiva como a prisão da província de Santa Fé.

Palavras-chave: evangelismo; governamentalidade; prisão reciprocidades; narrativas 


\section{Introducción}

La cárcel ha sufrido múltiples cambios a lo largo de su historia, algunos vinculados a sus diseños arquitectónicos, otros a la distribución temporo-espacial, otros a sus modelos de encierro. La prisión moderna aparece en escena como castigo humanizador frente a la pena de muerte y, sobre todo, viene a engarzarse con un sistema político-económico ávido de moralizar a sus trabajadores, enderezar desviados y gestionar los ilegalismos; la maquinaria capitalista debía funcionar a la perfección. Sumado a eso, la cárcel moderna se volvía expresión y materialización de un cambio en el orden de las sensibilidades (Spierenburg, 1984), de un conjunto social que ya no podía soportar las exhibiciones en la plaza pública, los desmembramientos de personajes condenados, las cabezas rodando entre charcos de sangre. El sintagma humanidad se reconfiguraba en nuevos sentidos y la prisión era la principal postulante para su redención.

En un mismo sentido, el neo-liberalismo contemporáneo imprime su lógica a las sensibilidades cotidianas definiendo un common sense penal en el que prevalece la prisión como depósito de los supernumerarios, aquellos que sobran, los que nunca se incluyeron, a quienes no quisieron incluir; en ese nuevo orden de sensibilidades la cárcel emerge -o mejor dicho va mutando- combinando viejas pretensiones correccionalistas con nuevas depositarias, sujeto enfermo pero también responsable de sí-mismo. El encierro, el aislamiento, la familia, la educación, el trabajo, la religión disputan los sentidos de la cárcel al tiempo que esta les asigna nuevas modalidades de ejercicio (Garland, 2005; Sozzo, 2009); modalidades que en la realidad carcelaria argentina se combinan desde sus orígenes (Caimari, 2004) singularizándose, contemporánea y paulatinamente, la preeminencia de un discurso penal sincerado en el fracaso correccionalista y concentrando sus esfuerzos en la seguridad interna. Caracterizaciones ontológicas que permiten cierto ordenamiento contextual y analítico pero que deben ser tensionadas encada sistema penitenciario atendiendo no sólo a las singularidades de los países y sus cárceles, sino también de los perfiles institucionales que asumen cada prisión.

Asimismo, a pesar de los cambios hay algo inmutable en la historia de la prisión moderna: la necesidad de gestionar la población encerrada bajo la premisa de aislar los individuos peligrosos del resto de la sociedad. Sobre esa problematización se configuró el dispositivo disciplinario (Bentham, 2005; Foucault, 2004)y bajo ese argumento se explican las modalidades de poder ejercidas en las cárceles contemporáneas, esas que pueden ser comprendidas desde el concepto de gubernamentalidad (Foucault, 2007; 2007 a), de la conducción de las conductas a través de la regulación, estableciendo acuerdos, reciprocidades, disponiendo permisividades pero también arbitrariedades. Por tanto, la obsesión de la prisión moderna y pos-moderna es gestionar la población encerrada y sobre esa gran preocupación dispone de elementos heterogéneos para avanzar en dicho objetivo; la religión es, tal vez, uno de los más importantes. Dispositivo religioso que en las prisiones argentinas tuvo presencia ya en las primeras experiencias penitenciarias modernas dado el estrecho vínculo entre Iglesia Católica y Estado Argentino ${ }^{1}$. Catolicismo fuertemente interpelado a partir de 1983 cuando al retorno de la democracia cuestione la inacción y connivencia de la Iglesia durante el período dictatorial (1976-1983). Fue a partir de entonces que el dispositivo religioso evangélico pentecostal (DREP) se dará una estrategia seria y sistemática de ingreso a las cárceles con una expansión que resultará, hasta la actualidad, indefinida.

El presente trabajo se propone indagar el papel que ocupa el dispositivo religioso-evangélico-pentecostal, en tanto táctica de gubernamentalidad, en la gestión de la población encerrada en Argentina tomando como caso el Servicio Penitenciario de la Provincia de Santa Fe (SPS) a partir de interrogarnos sobre sus orígenes, crecimiento y consolidación en las cárceles santafesinas (Argentina). Para ello, describiremos las trayectorias e interacciones de los pastores evangélicos en el entramado institucional de la prisión, nos preguntaremos sobre el ordenamiento social que define a los pabellones iglesias, y el conjunto de reciprocidades y narrativas que lo sustentan. Dispositivo generador de efectos concretos como la pacificación interna que le permiten, al pentecostalismo carcelario, posicionarse como una de las formas predilectas de regulación de las conductas en las prisiones argentinas ${ }^{2}$.

Partiendo de un enfoque cualitativo y desde una perspectiva interpretativa (Vasilachis de Gialdino, 2006), el trabajo de campo sobre el que fundamos los análisis de este artículo está construido en base a observaciones participantes y entrevistas en profundidad con detenidos de los pabellones 2, 5 y 6 de la Unidad Penitenciaria (UP) No. 11 (cárcel de máxima seguridad), los pabellones 1 y 2 de la Unidad Penitenciaria No. 3 de la ciudad 
de Rosario y los pabellones 5 y 10 de la UP No 6 (cárceles de mediana seguridad), todos autodenominados “cristianos” o "iglesias”. Las tres cárceles mencionadas pertenecen al Servicio Penitenciario de la Provincia de Santa Fe y, como todas las prisiones ubicadas en su territorio, responden a la órbita administrativa del gobierno provincial. Las observaciones se realizaron participando de instancias rituales en los pabellones-iglesia (cultos, pactos y estudios bíblicos) mientras que los entrevistados fueron seleccionados a raíz de dos criterios centrales como tener una estadía mayor de 6 (seis) meses en la prisión y que superara los 2 (dos) meses en el pabellón "iglesia". Sumado a esto, se realizaron entrevistas con distintos actores del entramado carcelario (Directores, profesionales y agentes del servicio penitenciario) y con el pastor evangélico Eduardo Rivello, señalado como uno de los responsables de insertar y consolidar el DREP en las cárceles de la provincia de Santa Fe. Por tanto, los análisis se fundan en un trabajo de campo integral que lleva ya 10 años, con la realización de más de 40 entrevistas en profundidad, cientos de registros de campo y un análisis documental que nos permiten esbozar las conjeturas aquí desplegadas ${ }^{3}$.

\section{Pagar derecho de piso. Democracia, silencios y dispositivo religioso}

La última dictadura militar en Argentina (1976-1983) introdujo profundas modificaciones en la estructura socio-política y cambios significativos en las dinámicas de sus instituciones. Una de ellas fue el servicio penitenciario, engranaje esencial de un esquema represivo que combinaba la violencia de Estado a manos del Poder Ejecutivo con un sistema de detenciones clandestinas cuyo enclave era, entre otros, la cárcel. Etapa de consolidación de una formación militarista en el servicio penitenciario (Cesaroni, 2013)y proceso de clausura y silenciamiento (De Olmo, 2001) que generará una coraza institucional bajo la idea de "cuerpo". Por tanto, todo elemento externo -entiéndase aquí organizaciones, instituciones, sujetos, etc.- que intentase o finalmente se alojase en su interior sería lentamente hostigado y expulsado ${ }^{4}$.

Ese fue el caso del DREP en las cárceles argentinas, proceso iniciado a pocos meses del retorno democrático en un contexto político que avizoraba múltiples aperturas y un evangelismo que buscaba expandir sus funciones tradicionales. Esto implicó el involucramiento de dicho credo con tareas educativas y asistenciales en instituciones como la prisión, y campañas masivas de evangelización que tuvieron en Argentina el escenario predilecto para predicar sobre el nacimiento de un nuevo hombre (o país) que buscaba sanar las heridas dejadas por la etapa más sangrienta de la historia vernácula (Wynarczyk, 2009). Sin embargo, el DREP en prisión estuvo signado primero por una etapa de rechazo absoluto, tanto de los penitenciarios como de los presos (Wynarczyk, 2009; Brardinelli, 2013).

En la provincia de Santa Fe se referencian algunos nombres como iniciadores de este movimiento en el contexto carcelario. Uno de ellos es el de Eduardo Rivello ${ }^{5}$, pastor de la iglesia inter denominacional "Cristo Vive” que en la actualidad se asienta en cinco cárceles de la provincia de Santa Fe, las Unidades Penitenciarias $n^{\circ} 1$ (Coronda), $n^{\circ} 2$ (Las Flores), $n^{\circ} 6, n^{\circ} 16$ (Rosario) y n 11 (Piñero). La primera visita de Rivello a la cárcel -la UP nº 1 -fue en el año 1986 y a partir de entonces empezó a viajar todas las semanas a la ciudad de Coronda (es oriundo de la localidad de Funes, a $20 \mathrm{~km}$ de la ciudad de Rosario y unos $150 \mathrm{~km}$ de Coronda)para ingresar los días de visita familiar. Por entonces, el escenario del SPS respecto al ejercicio de los credos religiosos era el de un catolicismo legalizado (capellanes y capillas) y minorías religiosas con autorización para entrar sólo en condición de visitas, recibiendo los mismos maltratos y arbitrariedades aplicadas por el SP a las familias de los detenidos. Por aquel entonces, el SPS hacía sentir su animosidad a todo factor externo que irrumpiera en el silencio carcelario, en un catálogo de extranjerismos que iba desde familiares de presos hasta credos religiosos no católicos:

"los primeros años comencé ingresando los Domingos en la visita haciendo la cola como corresponde [...]pagamos el derecho de piso y a la par de todos, ni hablar de entrar a la semana, muy poca llegada prácticamente casi nula [...]para hablar con los Alcaides, las autoridades” (Rivello, pastor)

Pagar derecho de piso significaba sentir el rigor de una institución de estructuras rígidas y celosas, heredera de una etapa oscurantista poco a poco interpelada por una transición democrática pretensiosa de inscribir un lenguaje de los Derechos en prisión (Hathazy, 2015). Pagar derecho de piso significaba un doble 
ejercicio de sumisión, el que ponía al DREP en una posición dispar respecto a la hegemonía del catolicismo y el que lo situaba en posición de extranjerismo, de "civil”:

"hubo resultados muy importantes que se sucedieron de gente que tomó el evangelio como un cambio de vida, como un nuevo estilo de vida [... y esos resultados de alguna manera llamaron la atención porque muchos de ellos llegaron a trabajar adelante por la faz de confianza en los casinos, a salir a limpiar adelante donde está la Jefatura [...] eso llamó la atención entonces un día de uno de los Directores, en aquel momento de turno, me llama, sorpresivamente” (Rivello, pastor)

Rivello relata que desde aquel llamado inesperado del Director de turno, y ante el reconocimiento de los efectos positivos de su presencia durante los días de visita (domingos de 10 a 12 hs), se le asignaría un día más (sábado) para predicar en la sala de una de las escuelas. Gesto que expresaba un reconocimiento luego del rechazo inicial pero también una excepcionalidad, ya que la UP nº 1 disponía sólo un día(sábado) para que todo credo religioso no católico ejerciese su práctica en un espacio y tiempo rigurosamente delimitados. En aquel entonces otra iglesia evangélica ya ocupaba ese lugar y ahora lo integraría también la de Rivello, generando esto que el DREP sea el único en predicar dos veces en la semana y con dos iglesias distintas.

A finales de los 80 Rivello comenzó a asistir dos veces por semana y a pesar de persistir un trato de hostigamiento y estricto control sobre sus prácticas por parte de los guardias cárceles, poco a poco fue generando mayores efectos en sectores de una población calificada como "revoltosa". Esto le valió la posibilidad de ingresar a un pabellón para armarlos primeros grupos - de 20, 30 personas en pabellones de 125- de presos evangélicos con cierta organización y bajo la coordinación de un pastor externo. Corría el año 1991 cuando el Director de la cárcel decide gestionar una entrevista entre Rivello y las máximas autoridades de la Dirección General del Servicio Penitenciario a los fines de que pueda contarle sus recorridos, tareas y logros. Allí obtuvola aprobación de las cúpulas penitenciarias a pesar de que los integrantes del cuerpo general seguían promoviendo acciones de rechazo hacia sus prácticas:

“muy resistido, muy resistido, no se podía, era muy...todo el personal estaba en contra, todo el personal, salvo el Director [...] que era la persona interesada en que el penal esté tranquilo. Era el que un poquito más apoyaba y aportaba y eso nos abría una puerta, como para llegar adentro de un penal, pero todo el personal estaba todo en contra, todo en contra, uno ya te digo era bastante maltratado, gente irrespetuosa, 'si vos venís a ver a estos porque vos sos más delincuente que ellos' o ‘vos sos de la familia de ellos', nada que ver, nosotros somos ministros como un sacerdote, una falta de respeto, nosotros somos ministros religiosos" (Rivello, pastor)

Indistinción sobre los actores externos, entre ellos los integrantes de credos religiosos no católicos, que poco a poco serán reconocidos -aunque no formalmente- por el SPS.

\section{Del rechazo a la aceptación. EIDREP en prisión y sus conquistas territoriales}

Transcurridos los 90, la violencia intra-muros crecía en el SPS y no se diferenciaba, en términos generales, de lo sucedido tanto en el Servicio Penitenciario Federal como en el Bonaerense (Motto, 2012). El motín de Sierra Chica (Buenos Aires), ocurrido en 1996, fue cristalización de los efectos producidos por una suerte de laissez faire punitivo cuyo eje era el desgobierno como estrategia de gobierno; modalidad fundada, entre otras cosas, en la delegación de poder (entiéndanse aquí control de ciertas dinámicas y espacios de la cárcel) del SP a los detenidos (Miguez, 2007). En Santa Fe, la Unidad Penitenciaria $\mathrm{n}^{\circ} 1$ era definida por entonces como el "termómetro" para medir el alto o bajo nivel de conflictividad del SPS. Durante la década de 1990 se registraron allí motines y huelgas que dieron cuenta no solo de las pésimas condiciones de vida de las prisiones santafesinas sino también del clima de tensión imperante. Sin embargo, en ese escenario de conflictividades se empezaban a distinguir algunos detenidos que, a comienzos de la década, habían asumido el papel de predicadores evangélicos en sus respectivos pabellones y no se involucraban de forma directa en los conflictos del penal -tanto entre internos como entre estos y las autoridades-: 
"era bueno toda la parte digamos, estratégica, la parte logística, de decir bueno, vamos a conquistar nosotros esos lugares, así que todo fue un proceso hasta que pudimos entrar a un pabellón a evangelizar dentro [...]la idea era hacer algo objetivo, algo concreto, de poder rescatar o reciclar lo recuperable, lo que se quiere recuperar en ese momento, porque a lo mejor mucha gente no se involucraba hasta que en el tiempo después se involucran porque claro, ve los avances, ve los cambios, ve los beneficios en otras personas” (Rivello, pastor)

“Antes se los veía como gente que no sumaba al servicio -a los pastores evangélicos-, entonces la relación era muy obligada, muy escueta, no era una relación de un vínculo [...] entonces si vos te pones a ver y hablar con la gente que viene ahora a trabajar externamente en los pabellones evangélicos, no hace 15 años que viene trabajando, hace más de 30 la mayoría. Después que empezaron a surgir las posibilidades de generar espacios evan...eee, darle sectores de alojamiento donde ahí tengan la posibilidad de hacer un pabellón conocidamente evangélico como se dice [...] lo que sí se nota fue un avance muy notorio. Yo lo que te puedo decir [...] llegaron estos espacios a hacer... lo que le dieron es una tranquilidad al servicio, lograron que dentro de esos espacios no haya hechos de violencia, se redujo el índice de hechos de violencia." (Director, UP n 11)

En el discurso de Rivello se reconoce una lógica de conquista territorial carcelaria que encontrará su máxima expresión cuando a comienzos del año 2001 se estableció el primer pabellón-iglesia de la UP $\mathrm{n}^{\circ} 1$ y de todo el sistema penitenciario santafesino. Para ser parte era imprescindible aceptar las normas definidas e impuestas por el DREP, sustentadas en la recuperación de numerosas prohibiciones carcelarias que hasta entonces nunca se habían querido, podido o sabido aplicar. En un pabellón iglesia no se podía- ni puede actualmentefumar, consumir estupefacientes y bebidas alcohólicas, producir enfrentamientos entre detenidos y con las distintas autoridades, entre algunas de las principales restricciones que lo diferenciaban de pabellones "mundanos”, tal como pasarían a calificarse quienes no adscribían a la "forma de vida” ${ }^{\circ}$ del DREP.

Disputa enunciada en términos espaciales pero configurada en territoriales, porque no se trataba de un problema de espacios sino de vínculos, asociaciones, disposiciones, en fin, relaciones de poder configuradas en nuevos territorios carcelarios, aquellos que ahora le disputaban a los actores penitenciarios no sólo un mercado económico (ya que la lógica religiosa desarmaba algunos negocios internos pero también generaba otros), sino una nueva configuración bio-política de la prisión, una redefinición de las estrategias de gobierno, de autonomías, de aperturas significativas si ubicamos esas “conquistas” en el marco de una institución que debió correr velos, dejar de practicar algunos silencios y empezar a marchar -lentamente y a destiempo- a la par de las aperturas democráticas.

En el caso de la provincia de Santa Fe podemos identificar un mojón en lo referido a una dinámica de reacción de la institución penitenciaria frente al DREP, que remite al hecho más sangriento de la historia penitenciaria santafesina: la "Masacre de Coronda" . Fue durante aquel episodio donde los pabellones-iglesias tuvieron un papel significativo en la regulación del conflicto, fundamentalmente evitando un espiral de violencia colectiva que podría haber generalizado el motín a toda la cárcel. En los años subsiguientes a la "Masacre de Coronda" empieza a notarse un reconocimiento sostenido a los pabellones iglesias en la UP $n^{\circ} 1$ y luego en el resto de las cárceles santafesinas; gesto que puede leerse como aceptación del SPS ante los efectos pacificadores que generaban. Actualmente, los datos referidos a la cantidad de pabellones iglesias en las principales cárceles santafesinas dan cuenta de ello: más del 60 \% de la población de la UP $n^{\circ} 1$ adscribe a la religión evangélica pentecostal; en la UP $\mathrm{n}^{\circ} 2$ (Las Flores), de un total de ochocientos setenta (870) internos quinientos cuarenta y nueve (549)están viviendo en pabellones evangélicos (Bosio, 2017), en la UP $n^{\circ} 3$ dos de sus diez pabellones (que albergan a más de 80 detenidos en un total de 270) se definen como espacios religiosos; la UP $\mathrm{n}^{\circ} 6$ cuenta con un total de 7 pabellones (sobre un total de 11) definidos como iglesias, la UP $n^{\circ} 16$ dos de su cuatro pabellones y finalmente, la UP $n^{\circ} 11$ con cinco de sus veinticuatro pabellones.

Esquema de crecimiento y potenciación del DREP en las cárceles santafesinas que, sumado a su papel en la cotidianeidad de las prisiones, interroga en términos de gubernamentalidad (Foucault, 2007; 2007 a), en cómo se vuelven un actor fundamental para pensar la gestión de la población encerrada. Disputas inicialmente definidas en términos espaciales pero que poco a poco adquieren sentido de territorialidad, un territorio enten- 
dido como "el espacio delimitado, circunscrito y políticamente habitado, administrado" (Segato, 2013, p. 76). Allí no se trata sólo de ocupar o ganar un espacio físico sino de configurar modalidades de gobierno que, paradójicamente, disputan, reactualizan y conservan sentidos de una maquinaria carcelaria cuyo objetivo central es que el día a día transcurra sin novedades.

\section{De aceptar a coordinar. Religión y gubernamentalidad carcelaria}

Dado los acontecimientos ocurridos en Abril de 2005 y el pronunciado avance del DREP en las cárceles provinciales resulta importante interrogarnos en qué entramado práctico-discursivo, y sobre qué conjunto de relaciones en la prisión, fueron consolidándose, sosteniéndose y creciendo los pabellones iglesias hasta constituirse hoyen pieza fundamental para el gobierno de las prisiones santafesinas. Una primera respuesta podemos encontrarla en el ordenamiento social de esos espacios, en el conjunto de reciprocidades desplegadas entre los "hermanitos" (así se nombra a quienes habitan un pabellón-iglesia) y los distintos actores del SP (principalmente su cuerpo general), y en las narrativas que sustentan el funcionamiento de dichos espacios.

El ordenamiento social del DREP cuenta con similitudes y diferencias respecto de la prisión. La principal similitud refiere a su estructura de mando; tal como sucede con el SP existe un orden jerárquico y verticalista cuyas variantes o matices estarán dadas por el pabellón-iglesia habitado -más o menos estricto en el seguimiento de las normas internas-. Las figuras que componen ese entramado de autoridades eclesiásticas intracarcelarias, cual si dibujo de una pirámide están distribuidas de arriba hacia abajo en el siervo, con-siervo, coordinadores, líderes (de mesas), asistentes de líderes y ovejas. Allí se establecen definiciones en las que se pautan no sólo los modos de convivencia sino también los esquemas de comportamiento aceptados y prohibidos:

“...en un pabellón mundano uno lo tiene a la policía como ortiva y al ser ortiva, y al tener el orgullo de choro o de lo que tenga el orgullo, uno a la policía la trata a los gritos o le dice cualquier cosa, lo insulta, no tiene orden con lo que es la autoridad y en un pabellón cristiano lo que se requiere es la autoridad, tenerle respeto, no saltear los escalones, porque si bien para dirigirse a la autoridad tenemos una serie de cadenas porque primeramente los que se dirigen solamente a la autoridad son los coordinadores o los siervos o consiervos, o sea, los líderes, asistentes y ovejas no se pueden dirigir directamente a la autoridad...caso que sea por algún motivo, por alguna duda, algo de eso, solamente te podes dirigir a la autoridad por un corte de luz que te suba la térmica, o para que... para pedirle alguna medicación o algo...solo para eso te podes dirigir" (Pablo, preso UP $n^{\circ} 11$ )

Estructura que, en prisiones contemporáneas fuertemente caracterizadas por la incertidumbre (Crewe, 2007) y la indeterminación (Crewe, 2018), habilita un precario pero preciso conjunto de certezas que permiten comprender algunas razones por los cuales los presos hermanitos habitan un pabellón iglesia. Mundo de la vida propia de dichos espacios que promueven instrumentalizaciones para que el SP pueda avanzar con su principal objetivo: producir el orden carcelario en términos de seguridad, de no conflictividad:

"la naturaleza impredecible del poder penal produce inseguridades importantes. Ante la incertidumbre, todo tiene significado y puede ser percibido como una prueba o amenaza. Los presos hablan de que 'están destinados a perder', tanto en el sentido de que las condiciones para acceder a la libertad son excesivamente exigentes como de que los pequeños errores parecen ser más importantes a la hora de valorar el riesgo, que años de buen comportamiento.” (Crewe, 2018, p. 9)

Dicha impredecibilidad en las prisiones contemporáneas está ligada también a la generación de ciertos grados de autonomía, referidos aquí no a la reducción de daños o sufrimientos del encarcelamiento (Sykes, 2017) sino a la transferencia de responsabilidades institucionales - del cuerpo penitenciario- al plano de las individualidades -del preso-. Son los propios detenidos quienes deben construir sus trayectorias vitales en el encierro, y en dicho transitar son responsables de si-mismos en lo que al conjunto de decisiones adoptadas refiere. En ese sentido, los sufrimientos generados sobre el preso ya no son responsabilidad del SP sino de símismo. Así, el mundo de la vida de los pabellones iglesias habilita modos de transitar la prisión ligados al tándem autonomización-responsabilización, y a partir de allí la construcción de un umbral mínimo de certezas- 
que no son absolutas porque también opera la discrecionalidad delos siervos - en relación a las "penalidades de la indeterminación” (Crewe, 2018: 8) promovidas por la prisión: “Más que acatar órdenes y demandas externas, están obligados a gobernarse a sí mismos adecuadamente, oa arriesgarse a las consecuencias que puede tener un comportamiento 'irresponsable’” (Crewe, 2018, p. 14).

Crewe esboza estas conclusiones para pensar el pasaje entre una prisión moderna que determinaba claramente los modos de resolver un conflicto -una golpiza, una sanción, etc.- frente a las contemporáneas en la que prevalece una opresión donde "el poder se experimenta como firme y blando, agobiante pero en cierto modo ligero". Así, el concepto de opresión captura "la sensación de no saber hacia dónde ir por miedo a acabar peor. Transmite el modo en cómo el poder opera de manera cercana y anónima, y funciona como un arnés invisible para el individuo" (Crewe, 2018, p. 17). En ese sentido, los pabellones iglesias disponen un entramado organizacional, vincular y gubernamental que disputa algunas incertidumbres de la prisión en lo referido al miedo de acabar peor -es decir, la muerte física directa-, combinándolo con las pretensiones punitivas de instalar la auto-responsabilidad como forma de vida:

"El compromiso para con Dios, lo que ellos tienen que hacer, ponele tengo cinco líderes que salen afuera ¿quién le da los estudios a los chicos? Entonces...tengo gente con salida transitoria, gente que trabaja afuera de acá pero después cumple con lo que tiene que cumplir, con lo que está establecido, un pacto, oran, estudio, cumplen con todo, ellos cuando ya entran pa el pabellón ya tienen que cumplir con todo, después lo que hacen afuera también, y también me interesa lo que hacen afuera porque adentro es una cosa, capaz una ovejita pero afuera es un lobo entendes, o anda fumando y da mal ejemplo a la iglesia y me entero -hace un gesto con las manos como que se va-, a ese le tenemos que decir que se retire del pabellón.” (Gonzalo, preso siervo UP n 6)

Por tanto, las narrativas de los detenidos al momento de justificar la decisión de habitar un pabellón iglesia están ligadas a la necesidad de alejarse de la violencia física directa y cotidiana del resto de los espacios de confinamiento. "Pelear por tus cosas" implica la posibilidad permanente del conflicto, el daño, la muerte. De allí que el mundo de la vida que configuran los pabellones iglesias sean para el SP un modo de habilitar tránsitos por el encierro ligados a la certeza de no morir pero, sobre todo, de reforzar y regular los esquemas de seguridad interna.

“...hace bastante que ya me traía a pensar de venirme a un pabellón iglesia, pero por ahí el orgullo no me dejaba venir, el orgullo me decía no, vos te tenes que quedar en ese pabellón, vos tenes que pelear por tus cosas, vos tenes que seguir como estás, hasta que me di cuenta que el orgullo es parte de un engaño y el engaño te lleva a la muerte porque es algo que no está concreto, es algo que estás engañado espiritualmente, estas cegado digamos, tenes los ojos pero no los utilizas, tenes los oídos pero tampoco los utilizas, y esto es lo que hoy me trajo hasta este pabellón pa poder buscar de Dios, pa buscar un cambio en mi vida, para poder dejar la droga, pa poder dejar la delincuencia” (Pablo, preso UP n 11)

Las narrativas ligadas a la muerte de un viejo hombre por uno nuevo, del pasaje entre la clasificación de "cachivache" -categoría nativa que define así al preso que sostiene una posición de enfrentamiento al SP y sus pares- a la de "hermanito" no sólo se sustenta en el argumento de la "muerte al orgullo" sino que se traduce en prácticas concretas como no apelar a la agresión física inter-personal para la resolución de conflictos en la convivencia cotidiana, tanto entre detenidos como con el resto de los actores carcelarios. De esta forma, las narrativas evangélicas son utilizadas estratégicamente por el servicio penitenciario para perseguir su principal objetivo: gestionar la población encerrada bajo los criterios del control y el gobierno.

"Si nosotros le ofrecemos un pabellón, por decirte, nosotros acá tenemos tres pabellones evangélicos y a mí me dan resultado, responden con conducta, con buena convivencia, con respeto, se responde con eso, yo creo que el resultado es bueno de parte de ellos hacia nosotros [...] Por eso te digo que desde el 2007 en el módulo Sur de Coronda que empezamos con el pabellón 4, después se fue haciendo progresivo...los resultados que ellos dieron fueron buenos, antes sacabas gente muerta, antes te prendían fuego un pabellón completo y ahora no pasa, y lo demostraron” (Director, UP n ${ }^{11}$ ) 
“G2- Creo que de acá para allá es ellos, y está bien que se manejen, que haya una estructura

G1- A nosotros nos beneficia, imagínate que viene uno quilombero o algo, y acá eso no le va a quedar otra que calmarse y no fumar, sino te va a durar un día o dos y los echaban porque es una población grande, porque no podes...no hace nada uno sólo que entra sino...te la aguantas o no te la aguantas o sino bueno...” (Guardias-cárceles, UP n 6)

La estructura a la que remite la declaración del guardia cárcel encargado de la custodia del pabellón iglesia, refiere no sólo a la organización interna sino también al conjunto de prohibiciones establecidas para la convivencia cotidiana: no agredir a las autoridades y a los detenidos, no portar elementos corto-punzantes, no fumar, no consumir estupefacientes, no insultar, no portar teléfonos móviles y no escuchar música “mundana” (principalmente cumbia). En cuanto a los deberes, el listado resulta menor aunque se modifica según el lugar ocupado en la estructura de la iglesia: participar activamente de las ceremonias religiosas (cultos, pactos y estudios bíblicos), mantener limpias las celdas y el pabellón, cocinar, entrevistar a los detenidos que pretenden ingresar al pabellón (siervo) y almacenar mercadería en freezers comunes.

Sumado a eso, la estructura refiere al conjunto de reciprocidades y transacciones intra-carcelarias acordadas con el SP que permiten una modalidad de convivencia ligada a la no-conflictividad. En ese sentido, las narrativas de los detenidos permiten observar no sólo los mecanismos disciplinarios desplegados en el ordenamiento social del pabellón iglesia sino también y, particularmente, las apropiaciones que el SPS realiza para la construcción del orden carcelario. Allí, las representaciones que los presos hermanitos esbozan sobre las autoridades dialogan con las pretensiones securitarias del SPS:

“Tenés que ir comprometiendo más con Dios o con la iglesia, vos te comprometes con Dios a medida de que vos vas haciendo. Todas las autoridades son puestas por Dios, todos los roles te los da Dios, no te lo da el hombre, sino cuando uno va perfeccionando su corazón Dios lo va viviendo porque Dios nos engendró, Dios nos puso en el vientre de nuestra madre, no es cierto, y Dios sabe cuál es el pensamiento de cada uno y el sentimiento de cada uno, si realmente es buscarlo de corazón o estar perdiendo tiempo, porque sino lo buscas más que chapearla sería, la buena palabra, perder el tiempo” (Cristian, preso UP $\left.n^{\circ} 11\right)$

En ese sentido, y más allá de las múltiples motivaciones que pueden llevar a los presos hermanitos a habitar un pabellón iglesia ${ }^{8}$, la autoridad se torna una noción fundamental para comprender las diferentes modalidades de sus trayectorias. Una autoridad entendida como aquella a partir de la cual "el agente puede cambiar el dato humano exterior, sin experimentar una reacción, es decir, sin que cambie él mismo en función de su acción”; desde allí es posible reconocer entonces cómo el ejercicio de la autoridad penitenciaria en los pabellones iglesias "no sólo no es lo mismo que emplear la fuerza (la violencia), sino que ambos fenómenos se excluyen mutuamente” (Kójeve, 2006, p. 36):

“Así el guardia -y también los Directivos- [...] normalmente descubre que su mejor curso de acción es hacer 'tratos’ o ‘negocios’ con los cautivos. En efecto, el guardia compra sumisión u obediencia en ciertas áreas tolerando la desobediencia en otras” (Sykes, 2017, p. 111)

Negociaciones que en los pabellones iglesias remiten a un conjunto de reciprocidades -positivas y negativas- configuradoras de escenarios carcelarios “sin novedades”, fundamentalmente en lo referido al ejercicio de la violencia física directa entre detenidos, y de estos frente a las autoridades. Reciprocidades entendidas como vínculos que, en una comunidad carcelaria, exceden la estructuración jerárquica y burocrática de la institución. Mecanismos de reciprocidad que alternan entre sus formas positivas donde cada parte involucrada recibe un beneficio y las negativas donde quien domina impone sus intereses para no provocar un daño mayor a los dominados (Miguez, 2007). En ese sentido, reconocemos en la dinámica de los pabellones iglesia un juego de reciprocidades intra-carcelarias que se mueven entre la cooperación y la imposición. Cooperación (reciprocidad positiva) porque existe un acuerdo explícito entre las autoridades del SP y las religiosas (internas y externas) a partir del cual los detenidos del núcleo duro aseguran el mantenimiento del orden interior de los pabellones (basándose en un férreo control y regulación de las normativas internas), e imposición revestida de 
cooperación -y a la inversa- porque lo que los integrantes del pabellón-iglesia reciben a cambio de la pacificación es una reducción en los umbrales de control. La vigilancia sobre sus prácticas no son tan estrictas (porque de hecho esa vigilancia la realiza el núcleo religioso), se les habilita otro tipo de movimientos en la cárcel, se permite la realización de actividades no autorizadas en otros pabellones o se facilita la utilización de elementos poco frecuentes en otros espacios de la prisión (por ejemplo, instrumentos musicales). Las requisas serán menos invasivas, las visitas autorizadas con mayor y mejor frecuencia, los movimientos menos controlados, los pedidos más escuchados.

Sin embargo, lo que instala aquel juego de cooperación es una indeterminación de los medios y formas a partir de los que se resuelven los conflictos internos (tanto entre detenidos como entre éstos y las autoridades). Para ello, sostendrán los "hermanitos", hay que "morir al orgullo", frase que condensa el sentido de dejar de hacer lo que se hacía antes como responder con agresiones (insultos, golpes, etc.) ante una arbitrariedad del SP. Ahora el procedimiento es diferente y allí se cristalizan reciprocidades cuyos límites entre la cooperación y la imposición se vuelven sinuosos, donde el abuso y las arbitrariedades del SP pueden ser leídos como una prueba de Dios:

“El camino de Dios es para valientes dicen...por ahí se te acontecen pruebas, luchas que Dios...son de parte de Dios porque Dios quiere ver la fe a ver si vos le estás creyendo a él a ver si verdaderamente vos estás buscando un cambio, si realmente crees en él principalmente, y por eso te pone una prueba, te pone una prueba, una lucha, y si vos la pasas te viene una victoria ¿por qué? Porque Dios te bendice en abundancia, por eso se apartan muchos porque en la prueba te dan lugar a lo que te está aconteciendo.” (Cristian, preso UP n 11)

Pruebas que pueden reconocerse en la narrativa de las prosperidades como elemento fundamental para el tránsito y permanencia cotidiana en los pabellones iglesias. En primer lugar, reconocemos tres prosperidades funcionando con regularidad en la cotidianeidad del encierro: económica, sanitaria/afectiva y penal. Las dos primeras corresponden estrictamente a la cosmología evangelista pentecostal, mientras que la última es propia del contexto en el que se inscribe, el encierro ${ }^{9}$.

En primer lugar, la prosperidad económica remite a la posibilidad de sustentarse económicamente una vez egresado de la prisión- sin incurrir en el terreno de lo ilegal y conseguir un puesto de trabajo a raíz de los contactos (capital social) que la iglesia puede otorgar. Por otra parte, la prosperidad sanitaria/afectiva es la que menos referencia tiene a la solución de problemas físicos o a enfermedades crónicas características de la prisión (HIV, tuberculosis, etc.). En su lugar, se destacan dos dimensiones significativas de la vida en el encierro como la reconstitución de los lazos familiares y la recuperación en el campo de las adicciones (fundamentalmente el consumo de estupefacientes). Por último, distinguimos una prosperidad que aparece recurrentemente en las entrevistas y en registros de cultos y pactos: la penal, referida a los pedidos por una pronta resolución en términos positivos- de las causas penales de los procesados, a la posibilidad de acceder a libertades transitorias sin complicaciones y la configuración de un escenario futuro donde el delito no sea la opción más inmediata:

"Luego de ingresar al pabellón, los detenidos me invitan a participar del culto. Todos se juntan en el centro, se toman de las manos y comienzan a pedir por sus causas y la de otros compañeros. Entre el conjunto de voces, se escucha a uno de los detenidos que agradece a Dios por haberle otorgado los permisos a X, y aprovecha para pedirle por los propios” (Registro de campo, UP $\mathrm{n}^{\circ} 11$ ).

En ese sentido, se argumenta que ser parte del DREP habilita una prosperidad penal para quien lo transita. Esta narrativa permite entonces comprender no sólo el mundo de la vida de los pabellones iglesias, sino también de qué formad estos consolidan esquemas de regulación y producción del orden carcelario por parte del SPS:

“Aparte otra cosa que Dios hizo en mi vida...a mí me pedían 35 años en total y apelo ese pedido de 35 años y vuelvo a bajar con otro pedido de 35 años y no me quedo otra que pedirle a Dios, Dios ayúdame, ayúdame a zafar en esta y...abro la Biblia y Dios me da una palabra [...] cinco días seguidos abro la biblia así al azar y los cinco días seguidos Dios me da la misma palabra, iqué! le entregué mi causa a 
Dios, empecé a buscar de Dios, empecé a buscar de Dios, sin importarme lo que el...lo que el juez y el fiscal me quisieran dar por la causa, y....al tiempo Dios se glorificó, quede con doce, de un pedido de 35 años quedé con 12 años y cuatro meses” (Cristian, preso UP n 11)

A fin de cuentas el ordenamiento social, las reciprocidades y las prosperidades se articulan en un espacio-tiempo definido por la religión evangélica pentecostal que genera efectos concretos de pacificación en los pabellones-iglesias destinados para su ejercicio. Para el SP esto es visto ya no con el recelo de sus comienzos sino con cierta complacencia a punto de tal de haberse convertido, los pastores externos, en consultores informales de acciones políticas penales. Al tomarse decisiones en torno a cómo poblar una nueva prisión o asumir redefiniciones espaciales y habitacionales en las ya existentes, el DREP ocupa un lugar relevante.

"A medida que fue inaugurándose ésta cárcel, la 16, y que tomaron la Alcaidia -UP nº 6-,fuimos ocupando esos lugares con la gente de las comisarías que teníamos evangelizadas ¿Por qué? Porque cuando se abrieron esas cárceles justamente un pedido de la Dirección General es que nosotros ocupáramos los espacios para las iglesias porque siempre saben que estando la iglesia, cero problema, no solamente adentro de la iglesia, hoy hasta afuera de la iglesia, tal es así que cuando se inauguró ahora la última-la U16- , el Director General nos consignó dos pabellones de los cuatro, dos pabellones, bajamos 120 de Coronda y otro grupo de comisaría para establecer dos sectores cristianos” (Rivello, pastor)

Sumado al relato de Rivello sobre la U16 (última cárcel inaugurada en la provincia de Santa Fe), uno de los casos más significativos fue el sucedido en el año 2014 cuando el SPS propuso trasvasar dos pabellonesiglesias completos de la UP $n^{\circ} 11$ a la UP $n^{\circ} 6$ (inaugurada como cárcel ese año), para que sus integrantes empezasen una minuciosa tarea de evangelización en los 11 pabellones que la componen. Decisión inconsulta con los detenidos pero efectiva en tanto la UP $n^{\circ} 6$ cuenta actualmente con 7 pabellones-iglesia. El trasplante como técnica de gestión poblacional le permitió al SPS ajustar perfiles institucionales; así, la UP n 11, cárcel de máxima seguridad, se consolida para los presos santafesinos como la prisión menos deseada, mientras que la UP $n^{\circ} 6$ adquiere el perfil de una cárcel de conducta donde la conflictividad se reduce casi a su mínima expresión. Significativo crecimiento y avance del DREP en las prisiones santafesinas y marcado interés del SPS por potenciar aquellos espacios que, a fin de cuentas, logran que las novedades penitenciarias poco tengan que ver con los conflictos internos.

\section{Conclusiones. Religión, bio-política y encierro(s)}

Al comienzo de este trabajo proponíamos dejar sentados algunos planteos en torno a los cambios del dispositivo carcelario para pensar cuánto de continuidad y de discontinuidad existe entre la prisión moderna, las modalidades de castigos previas (fundamentalmente la pena de muerte) y la cárcel actual(pos-moderna, posfordista, post-disciplinaria, neo-liberal o pos-neoliberal, entre algunas de sus definiciones). A partir de allí, lográbamos inferir que muchas de las características asignadas a las cárceles de hoy pueden rastrearse ya en el siglo XIX, no de idéntica forma pero sí como en una suerte de ritornelo que coloca a la prisión actual disputándose modos de gestionar el encierro y recuperando elementos correccionalistas que, en un mismo gesto, son desestimados por la práctica cotidiana que prioriza, ante todo, la seguridad interna. Paradojas carcelarias que conviven y hacen funcionar una maquinaria habilitadora y deshabilitadora, que permite nuevos modos de vivir o estar, y en esos modos de habitar la prisión una serie de configuraciones estratégicas para gestionarlas.

Entonces, si el DREP define un ordenamiento social y unos modos de relacionarse habilitantes de una regulación social basada en la disciplina y el orden, en el cuidado del sí-mismo, en la ephimeleia pero también en la bios de quienes lo integran, en el cuidado de los otros; y si el SP permite la creación, consolidación y crecimiento de dichos espacios en tanto sus efectos principales remiten a la pacificación interna de la prisión, a la definición de territorios auto-regulados que recuperan el entramado normativo de la prisión combinándolo con el aspecto informal de las reciprocidades (que tantos réditos, y en muchos casos descréditos le otorga a los miembros del SP), no debe resultarnos disonante que podamos hablar aquí del DREP como elemento central del entramado bio-político de la prisión. En ese sentido, la población carcelaria, su gestión, es un problema biológico y de poder (Foucault, 1996). Puesta en juego de los conceptos en una trama de significaciones donde 
es posible reconocer, en el funcionamiento del DREP, el interés por parte del SP de actuar sobre la población en términos colectivos; todo a los fines de anular los hechos aleatorios en la cotidianeidad del encierro, todo en busca de propiciar equilibrios internos. En ese sentido, resulta interesante reconocer cómo se articulan un conjunto de tácticas de gubernamentalidad con el objetivo de que esas aleatoriedades no se expresen en clave de auto-incriminación institucional.

Regular la vida, de eso trata, y en esa regulación será indispensable no sólo el disciplinamiento de buena parte de ella sino también la inscripción de mecanismos diferenciales que, sobre argumentos conductuales (parámetro de clasificación subjetiva por excelencia en las prisiones), habiliten distintos modos de gestionarla. Una vida concebida en riesgo permanente y de allí una de las características de las prisiones de hoy: la gestión de riesgos. Lo importante parece ser, cada día más, que los datos cierren, que las estadísticas oficiales muestren la inexistencia de muertes, que las cintas puedan descolgarse sin cuestionamiento alguno, en definitiva, que los números se plasmen en un juego de acuerdos y negociaciones que ponen a la balanza punitiva en el vaivén de las cesiones y los miramientos, en un esquema de delegaciones que nunca dejarán de ser revisadas. A fin de cuentas, la aleatoriedad de la prisión, de su población y de quienes la gestionan, marcará los pasos de esa pesada, oscura pero-paradójicamente- siempre cambiante institución destinada a neutralizar, enderezar o simplemente administrar la conducta de los otros.

\title{
Agradecimientos
}

El presente artículo es un avance de investigación del proyecto de Carrera de Investigador titulado "Transformaciones en las estrategias de gobierno del sistema carcelario argentino: El dispositivo religioso como táctica de gubernamentalidad sobre la población encerrada en el período 1983-2017. El caso del Servicio Penitenciario santafesino”, financiado por el Consejo Nacional de Investigaciones Científicas y Técnicas de la República Argentina (CONICET)

\section{Notas}

\begin{abstract}
${ }^{1}$ En otros países latinoamericanos el vínculo religión y Estado adquirió formas y sentidos divergentes como, por ejemplo, en México donde en 1879 se decretó la prohibición de prácticas religiosas oficiales en las cárceles estatales. Definición que no estaría exenta de
\end{abstract} contradicciones y tensiones identificables, inclusive, hasta la actualidad (Siguenza Vidal, 2016)

${ }^{2}$ En el presente artículo nos centraremos en el caso de la provincia de Santa Fe, pero es importante dar cuenta de la destacada producción en esta temática en Argentina (Algranti, 2012, 2012 a; Algranti y Brardinelli, 2017; Andersen, 2012, 2015; Daroqui, 2009) y otros países latinoamericanos (Lenita Scheliga, 2005; Nunes Dias, 2005; Ordoñez Vargas, 2012; Rodrigues, 2005; Concha, 2009; Marín Alarcón, 2016; Marín Alarcon y Bahamondes Gonzalez (2017); Restrepo Zapata y Moreno Baptista, 2011).

${ }^{3}$ El trabajo de campo integral referenciado en este artículo fue iniciado en el año 2009 en el marco de nuestra tesis doctoral titulada "Procesos comunicacionales y subjetivos en prisión. Los sistemas de insumisión en situaciones de egreso carcelario. El caso de la Unidad Penitenciaria nº 3 de la ciudad de Rosario” (2013). Allí nos propusimos el análisis de operaciones discursivas (paradojas, aporías y juegos del lenguaje) como tácticas de resistencia a los sistemas de sumisión de la prisión. La religión fue una de las materialidades discursivas emergentes y sobre la cual se esbozaron algunas de las principales conclusiones. En el año 2013, en el marco de un proyecto de investigación post-doctoral primero y luego de Carrera de Investigador del CONICET, comenzamos un trabajo de campo con el objetivo general de indagar el funcionamiento del dispositivo religioso como táctica de gubernamentalidad del servicio penitenciario santafesino. El trabajo de campo referenciado en este artículo es el resultante de las observaciones participantes y entrevistas en profundidad realizadas desde Abril de 2013 y hasta Marzo de 2018 en las principales cárceles del sur de la provincia de Santa Fe (UP nº 3, 6 y 11).

${ }^{4}$ Sobre algunas características que la dictadura militar imprimió al Servicio Penitenciario Santafesino ver Manchado y Narciso (2011; 2013)

${ }^{5}$ Oscar Jesús Sensini es el otro nombre referenciado como iniciador del pentecostalismo carcelario en Santa Fe. Sensini comenzó a transitar las cárceles a finales en 1988 y a mediados de la década del 90 inauguró, junto a su esposa Maricarmen Sensini, la iglesia "Redil de Cristo". De denominación pentecostal, cuenta actualmente con más de 5000 miembros y su sede central está en la zona sur de la ciudad de Rosario. Actualmente posee pabellones-iglesias en las UP $n^{\circ} 1, n^{\circ} 3$ y n $^{\circ} 6$.

${ }^{6}$ Quienes habitan un pabellón iglesia refieren a la práctica religiosa como una “forma de vida” y no como una religión, de allí que recuperamos esa definición nativa para comprender la cosmología puesta en juego en la cotidianeidad de la encierro.

${ }^{7}$ En abril de 2005, internos de dos pabellones de la UP n 1 se "enfrentaron" ocasionando la muerte de 14 detenidos, en la que fue 
conocida como la peor tragedia de la historia del SP santafesino.

${ }^{8}$ Existen tres figuras que permiten comprender algunas de las motivaciones que llevan a los presos a transitar un pabellón iglesia: a) los refugiados, viven allí por tener conflictos con detenidos de otros pabellones y no ser recibidos en espacios comunes; b) los convencidos, que tienen una larga trayectoria en el encierro y han decidido transitar cierta etapa de la condena alejados de la conflictividad de los pabellones comunes o quienes han logrado realizar un pasaje de aquella primera condición de refugiado a convencido, luego de involucrarse con las prácticas religiosas dispensadas en la iglesia, y c)los convertidos, que admiten una adhesión total a la religión y , una vez alcanzada la libertad ambulatoria, siguen asistiendo a la iglesia evangélica externa. Clasificación que, hacia el interior del pabellón, es la que se auto-asignan todos los presos entrevistados a pesar de todavía no haber recuperado la libertad ambulatoria; definirse como convertidos es un reaseguro simbólico y material para permanecer y un registro de visibilidad -hacia estamentos superiores- del compromiso asumido con la iglesia.

${ }^{9}$ Sobre los discursos que definen a las narrativas pentecostales en el encierro en tanto que prosperidades (sanitaria, económica y penal), fueron analizados en profundidad en Manchado (2017).

\section{Bibliografía}

Andersen, M. (2012). Los pabellones evangelistas en las cárceles del Servicio Penitenciario Bonaerense. Antagonismos entre las perspectivas micro y macrosociológica en el estudio de la prisión, en Grupo de Estudios sobre Sistema Penal y Derechos Humanos. Seminario de estudios comparados sobre las estrategias del gobierno de la cárcel neoliberal en Argentina y en Francia, pp. 188-205. Buenos Aires,Argentina: Universidad Nacional de Buenos Aires.

(2015). Administrando la violencia, el miedo y la miseria en el gobierno de la cárcel. Los pabellones de 'refugio' o 'resguardo' como tecnología penitenciaria de gobierno neoliberal. En II Jornadas de Sociología de la Facultad de Ciencias Políticas y Sociales de la UNCuyo, Facultad de Ciencias Políticas y Sociales de la UNCuyo, Mendoza, Argentina.

Algranti, J. (2012). ‘Cuando ellos tengan dos mil años, hablamos!’ Sociología de los capellanes en las cárceles bonaerenses”, Revista Question(36), 1-15. Recuperado de http://perio.unlp.edu.ar/ojs/index.php/question/ article/view/1596, acceso 13/11/2013

(2012a). La realidad carcelaria y sus variaciones religiosas. Un estudio sobre las formas de habitar los pabellones evangélicos. Revista de Ciencias Sociales Segunda Época, 27 - 45.

Algranti, J. y Brardinelli, R. (2017). Contra el principio de excepcionalidad. Reflexiones sobre las creencias en condiciones de encierro. Revista Sociedad y Religión (48), 176-190

Bentham, J. (2005).El Panóptico. Buenos Aires, Argentina: Ed. Quadrata

Bosio, G. (2017). Nuevas configuraciones del estado: la religión en la gestión post-carcelaria. Ponencia presentada en XXXI Congreso ALAS, Montevideo, Uruguay

Brardinelli, R. y Algranti, J. (2013).La re-invención religiosa del encierro: Hermanitos, refugiados y cachivaches en los penales bonaerenses.Bernal, Argentina: Universidad Nacional de Quilmes

Caimari, L. (2004).Apenas un delincuente: crimen, castigo y cultura en la Argentina, 1880-1955, Buenos Aires, Argentina:Siglo XXI

Cesaroni, C. (2013).Masacre en el Pabellón Séptimo.Temperley, Argentina: Tren en movimiento

Concha, N. (2009). Libertad entre los cautivos: aproximación al proceso de construcción de la identidad carcelaria pentecostal en el Complejo de Cumplimiento Penitenciario en Alto Hospicio. En J. Sepúlveda (ed.), Voces del pentecostalismo latinoamericano: identidad, teología, historia III, pp. 101-120.Concepción, Chile: Red Latinoamericana de Estudios Pentecostales. 
Daroqui, A. (2009). 'Dios agradece su obediencia': la 'tercerización’ del gobierno intramuros en la cárcel de Olmos. Ponencia presentada en el XXVII Congreso ALAS, Buenos Aires, Universidad Nacional de Buenos Aires

Del Olmo, R. (2001).¿Por qué el actual silencio carcelario en América Latina? En R. Briceño León(comp.)Violencia, sociedad y justicia en América Latina. Buenos Aires, Argentina: CLACSO

Foucault, M. (1996).Genealogía del racismo.La Plata, Argentina: Ed. Caronte

(2004).Vigilar y Castigar: Nacimiento de la prisión. Buenos Aires, Argentina: Siglo XXI

(2007).Nacimiento de la biopolítica: curso en el Collége de France: 1978-1979. Buenos Aires, Argentina: Fondo de Cultura Económica

(2007a).Seguridad, territorio, población: curso en el Collége de France 1977-1978. Buenos Aires, Argentina:Fondo de Cultura Económica

Garland, D. (2005).La cultura del control. Barcelona, España:Gedisa

Hathazy, P. (2015).Castigar en democracia: la reconstrucción de los consensos punitivos de la pos-transición en los campos carcelarios de Argentina y Chile. EnSeminario Internacional Política y penalidad. Debates y perspectivas contemporáneas, Universidad Nacional del Litoral - CLACSO, Santa Fe

Kójeve, A. (2006). La noción de autoridad. Buenos Aires, Argentina: Nueva visión

Lenita Scheliga, E. (2005). Trajetórias Religiosas e Experiências Prisionais: A Conversão em uma Instituição Penal. EnRevista Religiões e Prisões (61), 75-86.

Manchado, M. (2015). Dispositivo religioso y encierro: sobre la gubernamentalidad carcelaria en Argentina. En Revista Mexicana de Sociología 77(2), 277-300

(2015 a).Las insumisiones carcelarias: procesos comunicacionales y subjetivos en la prisión.Rosario, Argentina: Río Ancho Ediciones

(2017). Las prosperidades restauradoras: el papel de las narrativas pentecostales en las estrategias de gobierno del sistema carcelario argentino. En Revista Dados, vol. 60 (1), 173-208, http://dx.doi.org/ $10.1590 / 001152582017118$

Manchado, M.; Narciso, L. (2011). De la ‘mística penitenciaria’ al progresismo penal: Continuidades y discontinuidades en la propuesta de una política penitenciaria progresista en la provincia de Santa Fe. En Actas $11^{\circ}$ Jornadas Rosarinas Antropología Sociocultural, Rosario, Argentina

(2013). De derechos e identidades: Una mirada sobre los efectos identitarios del 'Estado Penitenciario’ en agentes del servicio penitenciario de la provincia de Santa Fe. EnRevista de la Escuela de Antropología (19),57-72

Marín, N. (2016). Evangelismo carcelario en Chile: Análisis socioantropológico de comunidades religiosas en contextos de encierro. EnPolis Revista Latinoamericana [online]. (43), 557-580, http://dx.doi.org/10.4067/ S0718-65682016000100026

Marín, N. y Bahamondes, L. (2017). Adicciones, disciplinamiento y pentecostalismo carcelario en Chile: Reflexiones para iniciar un debate.Revista Sociedad y Religión(48), 214-236 
Miguez, D. (2007).Reciprocidad y poder en el sistema penal argentino. Del 'pitufeo’ al motín de Sierra Chica. En A. Isla (comp.) En los márgenes de la ley. Inseguridad y violencia en el cono sur,Buenos Aires, Argentina: Ed. Paidós

Motto, C. (2012).Evolución y gestión de la población encarcelada, diferencias y articulaciones entre el SPF y el SPB. En GESPyDH (Comp..) Seminario de estudios comparados sobre las estrategias del gobierno de la cárcel neoliberal en Argentina y en Francia,Buenos Aires, Argentina: Universidad de Buenos Aires

Nunes Dias, C. (2005). Evangélicos no Cárcere: Representação de um Papel Desacreditado. EnDebates do NER(8), 39-55

Restrepo Zapata, D. y Moreno Baptista, C. (2011). La conversión religiosa en centros penitenciarios: El caso de 'La Blanca’ de Manizales. Revista Virajes(13), 237-255

Rodrigues, G. (2005). Transgressão, Controle Social e Religião: Um Estudo Antropológico sobre Práticas Religiosas na Penitenciária Feminina do Estado do Rio Grande do Sul. Debates do NER(8), 9-20

Segato, R. (2013).La escritura en el cuerpo de las mujeres asesinadas en Ciudad Juárez. Buenos Aires, Argentina:Tinta Limón

Siguenza Vidal, F. (2016). ‘La entrada está en tus manos, la salida en las de Dios’. La religión como medio de rehabilitación de los presos en la cárcel de Belén y la penitenciaría de Lecumberri (1874-1900). Revista de Historia de las Prisiones (2), 206-222. Recuperado de http://www.revistadeprisiones.com/la-entrada-estatus-manos-la-salida-las-dios-la-religion-medio-rehabilitacion-los-presos-la-carcel-belen-la-penitenciarialecumberri-1874-1900/

Sozzo, M. (2009).Populismo punitivo, proyecto normalizador y 'prisión depósito’ en Argentina. En Revista electrónica Sistema Penal y Violencia(1), 33-65. Recuperado de http://revistaseletronicas.pucrs.br/ojs/index.php/ sistemapenaleviolencia/article/view/6632/4837

Spierenburg, P. (1984).The spectacle of suffering : executions and the evolution of repression : from a preindustrial metropolis to the European experience.New York, EEUU: Cambridge University Press

Sykes, G. (2017). La sociedad de los cautivos. Estudio de una cárcel de máxima seguridad. Buenos Aires, Argentina: Siglo XXI Editores

Vasilachis de Gialdino, I. coord. (2006).Estrategias de investigación cualitativa. Barcelona, España:Gedisa

Wynarczyk, H. (2009).Ciudadanos de dos mundos: el movimiento evangélico en la vida pública argentina 19802001.San Martín, Argentina: Unsam Edita 